https://doi.org/10.24201/aap.2021.330

INFORME

\title{
Corea del Sur y el coronavirus de las cosas
}

\section{South Korea and the Coronavirus of Things}

\author{
JUAN FELIPE LÓPEZ AYMES \\ https://orcid.org/0000-0002-5661-4445 \\ Universidad Nacional Autónoma de México, México
}

Recepción: 6 de octubre de 2020

Aceptación: 3 de noviembre de 2020

Resumen: 2019 concluyó con una notable aprobación a la administración del presidente Moon Jae-in, después de un año agitado, intenso y lleno de eventos que tendrán repercusiones en años por venir. Las reformas institucionales al sistema electoral, la fiscalía, la policía y la agencia de inteligencia también continuaron su turbulento curso en la arena legislativa y sólo se logró aprobar, no sin empujones, un nuevo esquema de representación partidista en la Asamblea Nacional (Yonhap 2019a). La diplomacia intercoreana tuvo reveses importantes que complican la meta de Moon de establecer un nuevo régimen de paz para la península coreana; las relaciones con Japón continuaron deteriorándose cuando las controversias sobre la historia entre ambos países invadieron el terreno de las relaciones económicas y culturales que habían logrado mantenerse al margen durante las últimas dos décadas. Por último, queda claro para todos que ninguna nación ha escapado de los trastornos ocasionados por la pandemia de covid-19 en 2020, aunque algunos han salido mejor librados que otros y Corea del Sur parece ser uno de esos casos.

Palabras clave: Corea del Sur; recuperación económica; covid-19; reformas institucionales; relaciones exteriores e intercoreanas. 
Abstract: 2019 concluded with an outstanding approval to Moon Jae-in's administration, after an agitated and intense year full of events that will continue to reverberate for the upcoming years. Institutional reforms to the electoral system, the prosecution office, the police, and the spy agency kept their turbulent track on the legislative arena, but only managed to get the approval of a National Assembly party representation reform, yet not without pushing and shoving. Inter-Korean diplomacy had important setbacks and will complicate Moon's goal to establish a new peace regime in the Korean peninsula; relations with Japan remained strained as controversies about bilateral history invaded the economic and cultural areas, which mostly had had their own untainted course for the last two decades. Finally, it is clear to everybody that no nation escaped from the great upheaval caused by the Covid-19 pandemic in 2020, although some had fared better than others, and South Korea seems to be one of those cases.

Keywords: South Korea; economic recovery; Covid-19; institutional reforms; foreign and inter-Korean relations.

\section{COVID-19. CONTROL DE LA EPIDEMIA}

La estrategia de la República de Corea (en adelante Corea del Sur) para la contención y control del contagio del virus SARS-CoV-2 ha sido frecuentemente referida en la comunidad internacional como un caso ejemplar, aunque no sólo por las medidas gubernamentales, sino también por la respuesta social. ¿Qué muestra este caso en cuanto a la confianza de la sociedad sobre la capacidad del gobierno para el control de la propagación y las medidas para la recuperación económica? En general, parece que la sociedad surcoreana considera que la estrategia del gobierno en el manejo de la epidemia por parte de la Agencia para el Control y la Prevención de Enfermedades de Corea del Sur $^{1}$ ha sido la adecuada en función del contexto económico, político, social y tecnológico del país. Lo anterior se demostró con el triunfo incuestionable en las elecciones intermedias el 15 de abril, cuando la sociedad dio su

\footnotetext{
${ }^{1}$ El 14 de septiembre el Centro para el Control y la Prevención de Enfermedades fue promovido como agencia independiente del gobierno central; el nuevo estatus significa que, entre otras cosas, tendrá más autonomía, autoridad y personal. La agencia será dirigida por Jeong Eun-kyeong, la afamada jefa del anterior KCDC.
} 
voto de confianza al partido en el gobierno para continuar la estrategia para responder a la crisis y sus secuelas. La mayoría obtenida por el Partido Democrático en esas elecciones ciertamente ha presentado una gran ventaja para impulsar, además, su agenda política.

A diferencia de otros casos de manejo autoritario que, aunque exitosos, han sido también criticados, Corea del Sur puede "promover" su modelo como un caso de éxito sin recurrir a aislamiento forzado o el cierre de fronteras. La base de la estrategia coreana se concentró en el uso pruebas masivas y el rastreo de contactos para identificar rápidamente a las personas posiblemente contagiadas y tratarlas inmediatamente antes de que la infección pudiera diseminarse sin control. Desde que se empezaron a hacer las pruebas el 3 de enero, 2329931 de ellas se han concluido (05/10/2020). ${ }^{2}$ Esto le otorgó a la autoridad sanitaria una certera capacidad de respuesta pronta en diagnóstico y aislamiento. Por ejemplo, el primer caso de covid-19 se reportó el 20 de enero y poco después el sistema de salud detectó que el origen del brote había sido la muy poblada ciudad industrial de Daegu, al sureste de la península. Se descubrió que dos terceras partes de los contagios estaban relacionados con un grupo religioso. Se hicieron entonces pruebas a más de 200000 seguidores de ese culto y aislaron a los infectados.

El manejo integral consistió en al menos siete aspectos. El primero y más importante, como se dijo arriba, fue la realización de pruebas masivas de hasta 15000 personas al día en las primeras semanas (más que cualquier otro país). Estas pruebas podían hacerse por múltiples razones, como cuando una persona experimenta cualquiera de los síntomas conocidos y se sospecha debido a la actividad previa con contactos que contrajeron el virus; cuando se llega de China, Europa o Estados Unidos; aunque una persona no tenga los síntomas, pero quiere saber, puede pagar la prueba de su propio bolsillo, si da positivo se le regresa el dinero. La disponibilidad de kits de pruebas (PCR, reacción en cadena de polimerasa), y su relativo bajo costo en Corea del Sur, tiene que ver con la participación de cuatro empresas privadas (pero financiadas por el gobierno) que garantizan el abastecimiento, y, para analizarlas lo más rápido posible, el gobierno creó una red de laboratorios públicos y privados que operan en todo el país. Una de las maneras más vistas para realizarse las pruebas era por los llamados drive-through, en los que se tomaba la

\footnotetext{
${ }^{2}$ Centro de Control de Enfermedades, Ministerio de Salud y Bienestar: http://ncov.mohw.go.kr/en/
} 
muestra en el mismo automóvil después de hacer fila en puntos asignados. En caso de dar positivo, la persona tenía que someterse obligatoriamente al aislamiento durante 15 días. Esta medida permitió al gobierno planear la atención sanitaria y sólo 10\% de los infectados requirió hospitalización.

La segunda medida fue suspender actividades sociales al solicitar encarecidamente el aislamiento social y recomendar, sin forzar, a no abrir espacios cerrados donde se congrega gente como instalaciones religiosas, bares y gimnasios. Se suspendieron clases en escuelas, lo cual retrasó el inicio del ciclo escolar y se recomendó a oficinas que el personal trabajara desde casa. El gobierno no impuso bloqueos ni restricciones de movimiento. A partir del $1^{\text {o }}$ de abril se solicitó que las personas procedentes del extranjero efectuaran un autoaislamiento por 15 días. En esos casos, las medidas de confinamiento sí eran estrictas y quienes no las siguieran o dieran información falsa durante el proceso de cuarentena serían portadores de una pulsera electrónica que monitoreara todos sus movimientos o bien podrían recibir penas de cárcel de hasta un año o multas de más de 8000 dólares (Yonhap 2020c).

Para hacer eficiente el impacto de las medidas de contención y control de las infecciones se llevó a cabo una campaña masiva de información sobre la enfermedad y los mecanismos de contagio, lo cual facilitó el cumplimiento de las disposiciones de confinamiento, distanciamiento social e higiene. Para ello se apostó a la ampliación del acceso a datos y transparencia de la información, lo que redundó en la confianza hacia la autoridad sanitaria. El gobierno envía avisos y novedades por medio de mensajes de texto, por lo que la población tiene información de manera expedita. Una ventaja importante es la experiencia colectiva de epidemias y pandemias anteriores que tienen la misma forma de transmisión (SARS en 2003, gripe porcina en 2009 y MERS en 2015). Se facilitó así la formación de equipos de respuesta rápida; asimismo, muchos coreanos ya estaban familiarizados con las prácticas de higiene, distancia social y uso de máscaras, por lo que no fue particularmente difícil incorporarlas a los hábitos cotidianos (la aceptación en el empleo de máscaras también es natural en Corea del Sur debido a que por años han sufrido los problemas con polvo amarillo procedente del desierto de Gobi en ciertas épocas del año).

Un último aspecto que ha destacado en el caso de Corea del Sur es el seguimiento por teléfono celular, compras con tarjeta y vigilancia por cámaras CCTV para monitorear la 
movilidad y determinar riesgos y patrones de contagio. Mediante una aplicación especial (supuestamente bajo consentimiento) se monitorea la movilidad de quienes están en cuarentena y se activa una alarma en caso de que se traspase el límite establecido; en la aplicación se tienen que registrar los síntomas dos veces al día (si no registra algo en un día el personal de seguimiento se pone en contacto con la persona). Con la aplicación también se puede detectar la cercanía y tiempo de exposición con alguien infectado, y crear una base de datos de casos y sus patrones de movilidad y rutas de transmisión (contagio). Un sistema de monitoreo como éste ya estaba instaurado y era funcional en Corea del Sur, por lo que aquellos que quisieron replicarlo como Australia o Reino Unido (Babones 2020) no lo lograron porque las aplicaciones no estaban suficientemente desarrolladas y, además, no era natural aceptar ser monitoreado de manera voluntaria. Además, el sistema funciona en Corea del Sur porque es uno de los países mejor comunicados mediante tecnologías de la información y comunicación, la mayoría de la gente tiene instalada la aplicación especial, ${ }^{3}$ y llevan su celular encendido y con batería a todos lados.

El Estado no requirió del uso de la fuerza física o policial para hacer cumplir las recomendaciones, ya que en general la población ha tenido comportamiento responsable. No obstante, siempre hay personas o grupos que violan las reglas y propagan el virus. En parte para eso desde finales de abril se implementó el uso de pulseras electrónicas rastreadoras y así evitar que salgan personas en autoaislamiento de los lugares designados (Yonhap 2020d). ${ }^{4}$

El uso de información personal mediante sistemas de localización de los teléfonos móviles y los sistemas de pago por tarjeta se ha restringido a detectar los posibles focos de contagio y sus ramificaciones, con lo cual se pudo contener rápidamente la infección. Esta intromisión a la privacidad no ha sido tan ampliamente cuestionada por la población, aunque sí hubo quienes advirtieron de un potencial uso negativo de datos personales. El resultado fue la rápida disminución de nuevos contagios a un dígito por casi un mes después del primer gran brote (la mayoría de los nuevos casos eran "importados" y no comunitarios). ${ }^{5}$ Lo

\footnotetext{
${ }^{3}$ La aplicación no interfiere con otras, por lo que está activa todo el tiempo.

${ }^{4}$ Ante la controversia sobre la privacidad, los infractores tienen la opción de usar la pulsera o pasar la cuarentena en instalaciones designadas por el Estado.

${ }^{5}$ Aun cuando al inicio de la pandemia Corea del Sur llegó a estar en el cuarto lugar con más casos diagnosticados en el mundo ( $1^{\circ}$ China, $2^{\circ}$ Italia, $3^{\circ}$ Irán), la tasa de mortalidad era de $0.6 \%$, la más baja de todos (en Italia la tasa era diez veces más alta en ese entonces).
} 
anterior fortaleció la confianza del programa de contención, en especial cuando se trata de un territorio densamente poblado (511 personas por kilómetro cuadrado); mientras que en mayo Corea sólo tenía poco más de 11000 casos confirmados y 263 muertes, México registraba más de 55000 y casi 6000 muertes. El 5 de octubre, Corea tenía poco más de 24164 casos acumulados confirmados y 422 decesos, mientras que México tenía 761665 y 79088 , respectivamente. ${ }^{6}$

El rebote en agosto fue una señal de advertencia para toda la población sobre el peligro de relajar demasiado el distanciamiento social y las medidas de higiene en lugares públicos cerrados. Por las características de contagio del SARS-CoV-2, sólo se requiere de un pequeño descuido aquí o allá para que las infecciones se propaguen de manera acelerada. En realidad, hasta que la vacuna adecuada o el tratamiento efectivo estén ampliamente disponibles será preciso que el gobierno y la sociedad consigan coexistir con el virus. Para fortuna de Corea del Sur, el gobierno ha comprobado ser competente al conservar los principios democráticos y reconocer la importancia de mantener el flujo de información abundante y transparente y asegurar la disponibilidad de kits de prueba. En el cálculo sobre costos económicos y políticos de la respuesta, el gobierno surcoreano parece haber acertado en su inversión en el desarrollo de los kits, ya que le resultó menos costoso hacer pruebas que soportar la carga de enfermos en el sistema hospitalario - que de por sí tiene serios problemas - y también ha sido políticamente menos costoso invadir la privacidad que dejar toda la responsabilidad de la contención a la sociedad.

Finalmente, como dice Emanuel Pastreich (2020), la convergencia de política, tecnología, el expertise y la modificación de conductas de la ciudadanía es lo que pone aparte a Corea del Sur con respecto a otros países, aunque no por ello está exenta de retos en el camino de proteger la vida y reactivar el crecimiento económico. El país también enfrenta retos sociales que se han visto agudizados durante la pandemia, como contener la estigmatización para que ciertos sectores vulnerables (o "diferentes") se presenten a hacer pruebas y, si fuera necesario, hagan cuarentena. Eso demuestra lo difícil que es ser diferente en la sociedad coreana. Por ejemplo, la estigmatización inicial a miembros de la secta religiosa donde se identificó el brote original y la vorágine de peticiones para cerrar la iglesia,

\footnotetext{
${ }^{6}$ Datos para Corea del Sur en: http://ncov.mohw.go.kr/en/, y para México en: https://coronavirus.gob.mx/datos/
} 
enviar a juicio a su pastor y hasta prohibir su culto; la estigmatización a la comunidad LGBT tras el segundo brote pues el club donde se propagó era un bar gay (en el barrio internacional de Itaewon), lo cual detonó una oleada homofóbica en redes y fuera de ellas; también se evidenció la estigmatización de extranjeros, pues se ha podido contener la propagación de manera relativamente eficaz entre los ciudadanos, pero fueron los casos importados los que mantuvieron la cuenta a la alza, hasta que llegó la segunda racha de infecciones grupales a mediados de agosto vinculadas con una iglesia y una manifestación antigubernamental en Seúl. Aunque la intensidad fue menor que la primera, resultó lo suficientemente notoria y preocupante como para elevar los niveles de distanciamiento.

GRÁFICA 1. Casos confirmados con SARS-CoV-2 y muertes, 10 de febrero-31 de diciembre de 2020

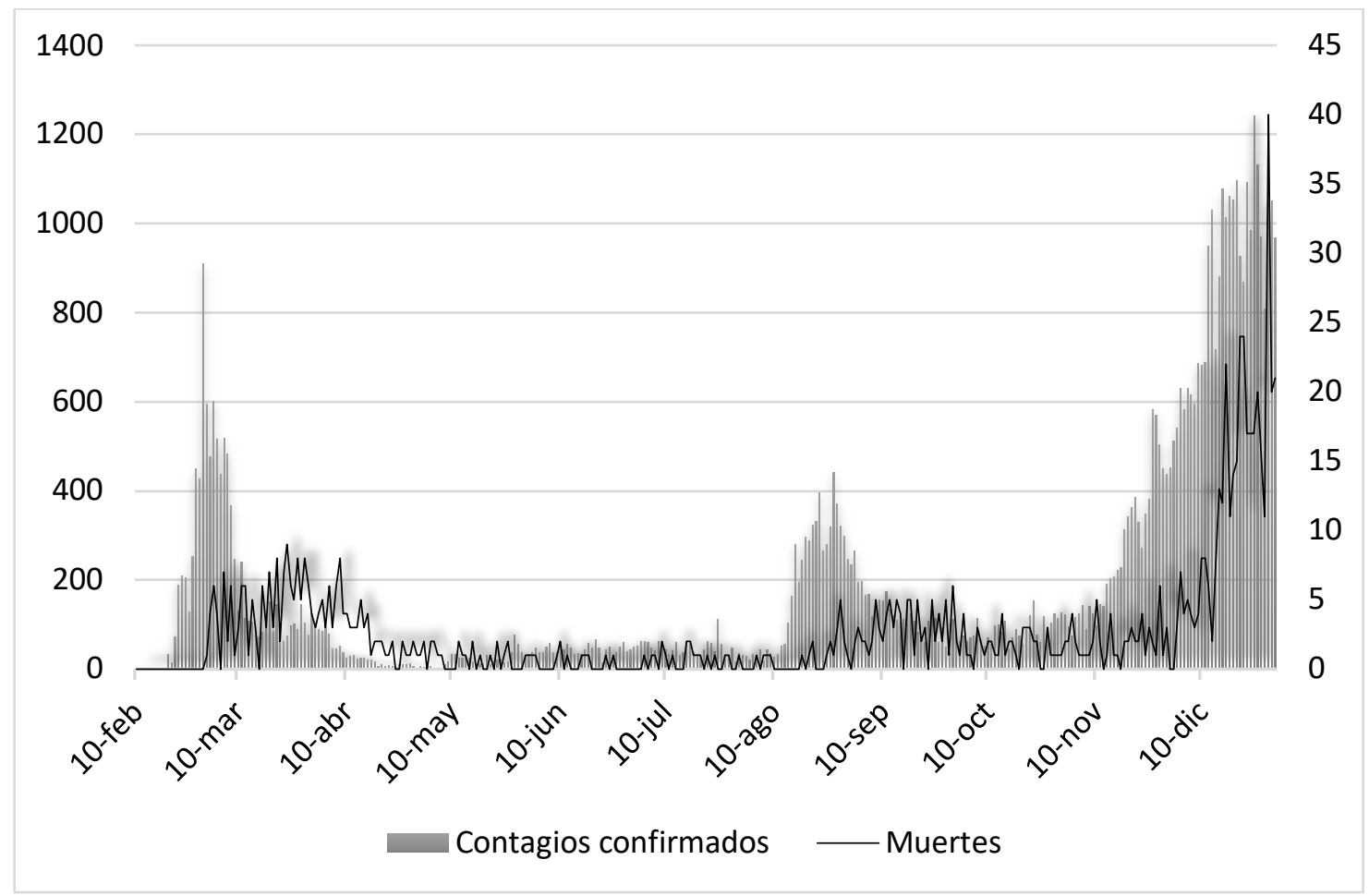

FuENTE: Korea Disease Control and Prevention Agency 2020.

La celebración de acción de gracias o Chuseok ( $1^{\mathrm{o}}$ de octubre) de este año, en la que tradicionalmente millones de personas viajan a los lugares de origen familiar para honrar a sus antepasados, tuvo que realizarse principalmente en el lugar de residencia. 


\section{ECONOMÍA Y NEGOCIOS}

En junio de 2020, la OCDE decía que "la pandemia de la covid-19 ha provocado la recesión económica más grave registrada en casi un siglo y está causando daños enormes en la salud, el empleo y el bienestar de la población". ${ }^{7}$ Ante esta perspectiva, compartida por todas las sociedades y gobiernos del mundo, la comunidad internacional observaba experiencias que pudieran aportar prácticas viables hacia la recuperación económica. Para Kong y Lee (2020), "la contención de la pandemia en Corea y la apertura puede presentar un camino para otros países que se encuentran emergiendo de sus respectivas cuarentenas. Sería una guía para vivir con el virus, más que tratar de eliminarlo". En ese orden de ideas, el vocero del Ministerio de Salud, Son Young-rae, dijo que resulta cada vez más claro que "la única opción viable" para la recuperación económica mientras persista el virus es "armonizar nuestra vida cotidiana con los esfuerzos de confinamiento", para lo cual es esencial contar con la cooperación de la gente y "que los ciudadanos, negocios e instituciones sigan las reglas" (Song, Kang y White 2020). Como todos los países, Corea del Sur se enfrenta al triple reto de aplanar la curva, contener o mitigar los brotes de contagio y reactivar la economía, todo al mismo tiempo.

Si bien con las medidas de salud pública establecidas por el gobierno surcoreano y la respuesta de la sociedad surcoreana en general se ha logrado mantener cierto control sobre la expansión de la enfermedad y su mortalidad, la crisis ha puesto otra vez en evidencia varios puntos vulnerables del país, especialmente en el ámbito económico, y también los ha amplificado.

El principal índice bursátil de Corea del Sur (KOSPI) tuvo sus peores días el 19 y el 23 de marzo de 2020, cuando la bolsa tocó fondo (el 17 de febrero el índice estaba en 2242.7 puntos, pero cayó 785 puntos en menos de un mes para llegar a su nivel más bajo: 1457.65 puntos el 19 de marzo). Ningún esfuerzo nacional o internacional lograban frenar la caída. El 15 de marzo, el KOSPI cerró en 1771.44 puntos, lo que condujo a la Comisión de Supervisión Financiera a establecer una moratoria de seis meses para la compraventa de instrumentos de corto plazo, medida que no se empleaba desde hacía casi nueve años. En los

\footnotetext{
${ }^{7}$ OECD, "La recuperación de la economía mundial camina sobre la cuerda floja". 10 de junio: https://www.oecd.org/ $\underline{\text { centrodemexico/la-recuperacion-de-la-economia-mundial-camina-sobre-la-cuerda-floja.htm }}$
} 
días inmediatos a la gran caída del índice KOSPI se experimentó una ligera recuperación gracias a que los inversionistas fueron alentados por acuerdos "swap" de divisas entre Estados Unidos y otras nueve economías alrededor del mundo, incluida Corea del Sur. La recuperación ha sido también muy acentuada, y le tomó poco más de cuatro meses para alcanzar los niveles que tenía a mediados de febrero. En agosto el índice mostró tendencia al crecimiento gracias a las expectativas de recuperación del mercado doméstico y extranjero; desde septiembre pueden verse fluctuaciones normales a cualquier mercado de capitales, aunque con tendencia a un alza moderada. ${ }^{8}$

Sin embargo, el comportamiento del mercado de capitales es, por lo general, independiente del resto del aparato productivo, especialmente en aquellas actividades que impulsan y sostienen la producción de bienes y servicios. En este caso, las perspectivas son mucho más precarias. En su boletín económico de septiembre, el Ministerio de Economía y Finanzas reportó que la producción de bienes y servicios, la minería y la construcción, las ventas al menudeo y la inversión en instalaciones registran en conjunto una baja con respecto al año anterior y así ha sido el año entero desde que la pandemia azotó el mundo (Ministry of Economy and Finance 2020c). El aspecto positivo es que varias de esas actividades, como la producción industrial y la construcción, muestran mejoría con respecto a los meses inmediatos anteriores, aunque las ventas al menudeo y la inversión en instalaciones suelen tener dificultades para reponerse.

Producto interno bruto (\% de cambio con respecto al periodo anterior)

\begin{tabular}{|c|c|c|c|c|c|c|c|c|}
\hline & \multicolumn{5}{|c|}{2019} & \multicolumn{2}{|c|}{2020} & \multirow[b]{2}{*}{$Q 3$} \\
\hline & Anual & $Q 1$ & $Q 2$ & $Q 3$ & $Q 4$ & $Q 1$ & $Q 2$ & \\
\hline PIB & 2.0 & -0.3 & 1.0 & 0.4 & 1.3 & -1.3 & -3.2 & 1.9 \\
\hline Agricultura y pesca & 0.3 & 5.8 & -5.5 & 2.9 & -1.5 & 3.7 & -9.5 & 1.8 \\
\hline Manufactura & 1.3 & -2.9 & 1.0 & 1.8 & 1.8 & -1.0 & -8.9 & 7.6 \\
\hline Construcción & -2.5 & -1.2 & 3.1 & -3.7 & 3.7 & 0.2 & -0.3 & -5.5 \\
\hline Servicios & 2.9 & 0.6 & 0.8 & 0.5 & 1.3 & -2.4 & -0.9 & 0.7 \\
\hline
\end{tabular}

FUENTE: Ministry of Economy and Finance 2020d, 44.

\footnotetext{
${ }^{8}$ Korea Stock Exchange KOSPI Index, Bloomberg. https://www.bloomberg.com/quote/KOSPI:IND
} 
Para el caso de Corea, el sector externo es particularmente importante como motor de crecimiento económico y, por consiguiente, es de los más castigados durante la pandemia debido a la recesión económica mundial y al incremento del proteccionismo en los principales mercados de exportación: China (+ Hong Kong), Estados Unidos y Japón absorben más del 50\% de las exportaciones surcoreanas (World Bank 2020). En abril las exportaciones disminuyeron $24.3 \%$ respecto al mismo mes el año anterior; las ventas a Estados Unidos, China, la Unión Europea y la ANSEA cayeron 14\%, 18\%, 13\% y 33\%, respectivamente (Ministry of Economy and Finance 2020a, 15). En agosto las exportaciones registraron una caída de $9.9 \%$ respecto al año anterior, lo cual apunta hacia una recuperación del mercado internacional para los productos coreanos. Esta vez la disminución a Estados Unidos fue de $0.4 \%$, respecto al mismo mes del año anterior, 3\% para China, 3\% para la Unión Europea y 18\% para la ASEA (Ministry of Economy and Finance 2020c, 14).

Balanza de pagos (millones de dólares)

\begin{tabular}{|c|c|c|c|c|c|c|}
\hline \multicolumn{2}{|c|}{ Periodo } & \multirow{2}{*}{$\begin{array}{c}\begin{array}{c}\text { Cuenta } \\
\text { corriente }\end{array} \\
7759.1\end{array}$} & \multirow{2}{*}{$\begin{array}{l}\text { Bienes } \\
8698.7\end{array}$} & \multirow{2}{*}{$\begin{array}{c}\text { Exportaciones } \\
46164.9\end{array}$} & \multicolumn{2}{|l|}{ Importaciones } \\
\hline 2019 & Septiembre & & & & 37466.2 & -2261.7 \\
\hline & Octubre & 7827.2 & 8028.2 & 49119.9 & 41091.7 & -1718.7 \\
\hline & Noviembre & 5974.8 & 7390.9 & 46497.3 & 39106.4 & -1893.9 \\
\hline & Diciembre & 4330.9 & 5027.6 & 48039.2 & 43011.6 & -2503.5 \\
\hline \multirow[t]{7}{*}{2020} & Enero & 1006.5 & 1928.8 & 43444.2 & 41515.4 & -2481.0 \\
\hline & Febrero & 6366.9 & 6419.6 & 41649.3 & 35229.7 & -1332.9 \\
\hline & Marzo & 5960.5 & 6655.4 & 46075.3 & 39419.9 & -1392.8 \\
\hline & Abril & -3331.1 & 625.1 & 36194.7 & 35569.6 & -1463.1 \\
\hline & Mayo & 2286.1 & 2501.2 & 34551.6 & 32050.4 & -481.3 \\
\hline & Junio & 6880.0 & 5867.3 & 40018.7 & 34151.4 & -1259.7 \\
\hline & Julio & 7451.8 & 6974.5 & 43202.2 & 36227.7 & -1107.6 \\
\hline
\end{tabular}

FUENTE: Ministry of Economy and Finance 2020c, 64. 
Exportaciones e importaciones (miles de millones de dólares, \%)

\begin{tabular}{lccccccccc}
\hline & \multicolumn{5}{c}{2019} & \multicolumn{5}{c}{2020} \\
\hline & Anual & $Q 1$ & $Q 2$ & $Q 3$ & $Q 4$ & $Q 1$ & $Q 2$ & $Q 3$ & Septiembre \\
\hline Exportaciones & 542.22 & 132.65 & 138.49 & 134.73 & 136.36 & 130.24 & 110.40 & 130.40 & 48.04 \\
(a-a, \%) & -10.4 & -8.5 & -8.7 & -12.3 & -11.8 & -1.8 & -20.3 & -3.2 & 7.6 \\
Importaciones & 503.34 & 123.80 & 128.77 & 124.96 & 125.81 & 121.86 & 107.98 & 113.60 & 39.35 \\
(a-a, \%) & -6.0 & -6.5 & -3.3 & -4.1 & -9.7 & -1.6 & -16.1 & -9.1 & 1.6 \\
Balanza comercial & 38.89 & 8.86 & 9.72 & 9.77 & 10.54 & 8.38 & 2.42 & 16.83 & 8.70 \\
\hline
\end{tabular}

FUENTE: Ministry of Economy and Finance 2020d, 14-15.

Parte de las vulnerabilidades de la economía surcoreana, además de su alta dependencia en el sector externo y en tres o cuatro mercados externos, es la concentración de casi 55\% de sus exportaciones en dos sectores: maquinaria, equipo eléctrico y electrónico, y automotriz (World Bank 2020). En abril el único bien que tuvo un crecimiento en las exportaciones fue el de las computadoras, justamente por el gran cambio en la práctica laboral y educativa generada por las medidas de distanciamiento en el mundo que se acomodaron al trabajo remoto, generalmente desde los mismos hogares de los trabajadores y las comunidades escolares. La venta de semiconductores, maquinaria, productos petroquímicos y buques cayeron con respecto al año anterior. En agosto, la exportación de computadoras volvió a mostrar crecimiento al igual que los aparatos electrodomésticos y los semiconductores, pero la venta de productos petroquímicos, buques, autopartes y dispositivos de comunicación inalámbrica fue menor a la correspondiente de 2019 (Ministry of Economy and Finance 2020a y 2020c).

La incertidumbre por la alta dependencia a la industria de exportación es particularmente preocupante porque Corea del Sur tiene poco o nada de control sobre el mercado internacional, máxime cuando sus principales socios han sostenido su propia guerra comercial, en la cual Corea es sólo un espectador, pero igual pierde por la gran cantidad de encadenamientos productivos ya establecidos en China.

El sector automotriz ciertamente ha sufrido durante la pandemia. Entre enero y agosto la producción tuvo el registro más bajo desde 2009, con 2206712 vehículos (2 637273 en 
el mismo lapso en 2019). Las exportaciones en aquel periodo fueron de 1137778 automóviles (1 608754 entre enero-agosto de 2019). En mayo se registró la peor caída al vender sólo 95791 vehículos en mercados extranjeros en 2020, cuando en mayo de 2019 se vendieron 225 191; esto representa una disminución de 57.6\% en el registro interanual; asimismo, el valor se redujo 54.1\%, principalmente por una menor demanda en el mercado estadunidense y europeo (Korea Automobile Manufacturers Association 2020). De enero a mayo de 2020, Hyundai Motors, la mayor armadora coreana, vendió 1288629 vehículos, mientras que en el mismo periodo de 2019 vendió 1748 911, lo que significa una contracción de 26 por ciento. ${ }^{9}$

Ante la severidad de la contracción económica, las grandes empresas llevaron a cabo acciones como reducir la producción o suspender servicios, reducir costos y vender activos, recortar salarios a ejecutivos y brindar licencias con y sin sueldo a empleados. Algunas de ellas lograron obtener préstamos de la banca de desarrollo, como el Korea Development Bank (KDB) y el Banco de Exportaciones e Importaciones (Eximbank). Por ejemplo, tras las políticas de confinamiento y restricciones de entrada por todo el mundo por el nuevo coronavirus, las principales aerolíneas surcoreanas suspendieron o reajustaron rutas y usos de flota para vuelos internacionales desde fines de marzo; Korean Air envió 70\% de los 20000 miembros de su plantilla a una licencia con sueldo durante seis meses a partir del 16 de abril, y buscaba vender parte de sus activos no esenciales para conseguir liquidez, además de recaudar alrededor de 826 millones de dólares con la emisión de acciones, y más de 992 millones de dólares del KDB y el Eximbank. En abril, Asiana también comenzó a colocar a sus 10500 empleados en licencia sin sueldo de 15 días, o hasta que las circunstancias del negocio volvieran a la normalidad. Los ejecutivos de esa aerolínea acordaron devolver $60 \%$ de sus salarios, aunque en su momento no dieron a conocer un periodo específico de dicho recorte de sueldos. El KDB y el Eximbank inyectaron 1405 millones de dólares a Asiana.

Si bien el gobierno surcoreano no cerró las fronteras, la movilidad internacional prácticamente se detuvo afectando severamente el sector turístico nacional y, como vimos arriba, el de la aviación. Por ejemplo, el turismo proveniente de China es uno de los

\footnotetext{
${ }^{9}$ En marzo, Hyundai Motors suspendió la mayoría de sus plantas en el exterior (China, Estados Unidos, República Checa, Turquía, Rusia, India y Brasil), las cuales reanudaron parcialmente sus operaciones en junio. Véase Yonhap 2020e.
} 
principales consumidores del sector en Corea del Sur, y en enero de 2020 había aumentado $22 \%$ respecto al mismo mes el año anterior, pero ya en febrero se contrajo $84.7 \%$, en abril 99.1\% y en agosto 97.1\%. Asimismo, otros servicios también tuvieron una caída importante en los primeros dos trimestres, aunque la mayoría ha logrado recuperarse a partir de mayo.

Servicios. Porcentaje de cambio respecto al periodo anterior

\begin{tabular}{|c|c|c|c|c|c|c|c|c|c|}
\hline & \multicolumn{4}{|c|}{2019} & \multicolumn{5}{|c|}{2020} \\
\hline & $Q 1$ & $Q 2$ & $Q 3$ & $Q 4$ & $Q 1$ & $Q 2$ & Junio & Julio & Agosto \\
\hline Índice de actividad de servicios & 0.3 & 0.3 & 0.6 & 0.7 & & -1.5 & 2.2 & 0.3 & -1.0 \\
\hline Mayoreo y menudeo & -0.6 & -0.3 & 0.5 & -0.3 & -3.8 & -0.1 & 2.2 & -1.4 & -1.5 \\
\hline Transporte y almacenaje & -0.4 & -0.3 & 0.6 & -0.6 & -8.9 & -10.3 & 2.6 & 1.4 & -2.3 \\
\hline Hoteles y restaurantes & -0.8 & 0.4 & -1.2 & 2.0 & -17.1 & -0.4 & 1.4 & 2.5 & -7.9 \\
\hline Información y comunicaciones & 4.0 & 0.5 & 0.3 & 0.4 & 2.6 & -1.7 & -4.6 & 2.3 & -2.4 \\
\hline Finanzas y seguros & 0.3 & 0.6 & 1.4 & -0.1 & 6.9 & 3.3 & 2.8 & 1.9 & 3.7 \\
\hline Bienes raíces y alquiler & -1.3 & -0.9 & 2.9 & 4.6 & 3.4 & -4.3 & 6.2 & 2.5 & -6.7 \\
\hline $\begin{array}{l}\text { Servicios profesionales, científicos } \\
\text { y técnicos }\end{array}$ & -0.9 & 0.9 & 0.2 & 0.5 & 0.3 & -2.2 & 5.7 & -2.5 & -3.2 \\
\hline Servicios a negocios & 0.0 & 1.7 & -0.5 & 3.1 & -8.9 & -6.0 & 0.7 & 0.6 & 0.2 \\
\hline Educación & -0.2 & -0.6 & 0.1 & -0.1 & -4.5 & -0.7 & 5.3 & -1.7 & 0.0 \\
\hline Servicios de salud y bienestar & 1.8 & 1.7 & 2.9 & 1.7 & -2.5 & 0.0 & -0.1 & 0.5 & 0.4 \\
\hline Entretenimiento y ocio & 2.6 & -1.4 & -1.4 & 3.2 & -20.2 & -27.1 & 10.7 & 7.2 & -8.6 \\
\hline $\begin{array}{l}\text { Membresía organizaciones } \\
\text { y servicios personales }\end{array}$ & -1.0 & 0.0 & -1.3 & 1.4 & -9.6 & 2.4 & 2.9 & -4.0 & -1.3 \\
\hline Saneamiento y desechos & -2.4 & 0.2 & 3.3 & 1.1 & 2.7 & -3.9 & 1.3 & -1.4 & -3.8 \\
\hline
\end{tabular}

FUENTE: Ministry of Economy and Finance 2020d, 19.

El impacto en la producción de bienes y servicios repercute necesariamente en el sector laboral, lo cual es de suma importancia para un gobierno que ha fincado su política económica en el crecimiento por ingresos y, por ende, en la creación de empleos y el aumento del salario mínimo. Estos objetivos no sólo fueron severamente perjudicados por la crisis causada por el coronavirus, sino que ha sometido al gobierno a una mayor presión en las finanzas públicas para sostener el modesto logro alcanzado durante 2019. Como 
mencionamos en la edición 2020 del Anuario Asia Pacífico, este objetivo y la implementación de medidas para alcanzarlo no estaban exentos de polémica.

Según estadísticas oficiales, en agosto se perdieron 274000 empleos, un poco menos que el mes anterior, cuando se perdieron 277 000. No obstante, la tasa de desempleo llegó a estar en $4.4 \%$ en el segundo trimestre, pero ha ido disminuyendo hasta llegar a $3.1 \%$ en agosto.

\begin{tabular}{|c|c|c|c|c|c|c|c|c|c|}
\hline & \multicolumn{5}{|c|}{ Empleo } & \multirow{2}{*}{\multicolumn{4}{|c|}{2020}} \\
\hline & \multicolumn{5}{|c|}{2019} & & & & \\
\hline & $Q 1$ & $Q 2$ & $Q 3$ & Agosto & $Q^{4}$ & $Q 1$ & $Q^{2}$ & Julio & Agosto \\
\hline Número de empleados (millones) & 26.46 & 27.26 & 27.38 & 27.36 & 27.39 & 26.75 & 26.85 & 27.11 & 27.08 \\
\hline Tasa de empleo & 59.6 & 61.3 & 61.5 & 61.4 & 61.4 & 59.9 & 60.0 & 60.5 & 60.4 \\
\hline $15-64$ & 66.0 & 66.9 & 67.1 & 67.0 & 67.3 & 66.1 & 65.6 & 66.0 & 65.9 \\
\hline $\begin{array}{l}\text { Crecimiento de empleo } \\
\text { ( } a-a \text {, miles) }\end{array}$ & 177 & 237 & 366 & 452 & 422 & 288 & -407 & -277 & -274 \\
\hline Manufactura & -143 & -64 & -76 & -24 & -41 & 6 & -55 & -58 & -50 \\
\hline Construcción & -7 & -1 & -1 & 26 & -50 & -8 & -61 & -23 & -6 \\
\hline Servicios & 240 & 295 & 391 & 399 & 466 & 186 & -353 & -240 & -215 \\
\hline Mayoreo y menudeo & -52 & -39 & -68 & -58 & -83 & -123 & -162 & -127 & -176 \\
\hline Hoteles y restaurantes & -5 & 56 & 95 & 104 & 98 & -3 & -193 & -225 & -169 \\
\hline Servicios de salud y bienestar & 196 & 126 & 168 & 174 & 155 & 158 & 124 & 161 & 160 \\
\hline Trabajadores asalariados & 223 & 295 & 427 & 514 & 482 & 311 & -262 & -92 & -113 \\
\hline Trabajadores permanentes & 334 & 347 & 491 & 493 & 603 & 580 & 381 & 346 & 282 \\
\hline Trabajadores temporales & -123 & -53 & -33 & -2 & -14 & -155 & -499 & -385 & -318 \\
\hline Jornaleros & 12 & 1 & -31 & 24 & -108 & -114 & -145 & -44 & -78 \\
\hline Trabajadores no asalariados & -45 & -58 & -61 & -62 & -60 & -23 & -145 & -185 & -161 \\
\hline Trabajadores auto empleados & -39 & -26 & -30 & -19 & -34 & -26 & -103 & -128 & -106 \\
\hline
\end{tabular}

FUENTE: Ministry of Economy and Finance 2020c, 20. 


\begin{tabular}{|c|c|c|c|c|c|c|c|c|c|}
\hline \multicolumn{10}{|c|}{ Desempleo } \\
\hline & \multicolumn{5}{|c|}{2019} & \multicolumn{4}{|c|}{2020} \\
\hline & $Q 1$ & $Q 2$ & $Q 3$ & Agosto & $Q 4$ & $Q 1$ & $Q 2$ & Julio & Agosto \\
\hline Número de desempleados (miles) & 1241 & 1176 & 946 & 858 & 891 & 1162 & 1226 & 1138 & 864 \\
\hline $\begin{array}{l}\text { Crecimiento de desempleo } \\
\text { (a-a, miles })\end{array}$ & 61 & 71 & -119 & -275 & -51 & -80 & 50 & 41 & 6 \\
\hline Hombres & 38 & 53 & -66 & -160 & -39 & -64 & -3 & 5 & -31 \\
\hline Mujeres & 22 & 18 & -53 & -115 & -12 & -16 & 53 & 36 & 37 \\
\hline Tasa de desempleo (\%) & 4.5 & 4.1 & 3.3 & 3.0 & 3.1 & 4.2 & 4.4 & 4.0 & 3.1 \\
\hline
\end{tabular}

FUENTE: Ministry of Economy and Finance 2020c, 22.

Y mientras las dificultades económicas golpean principalmente a trabajadores independientes y empresas pequeñas y medianas y a sus empleados, el gigante automotriz Hyundai Motors logró pactar el congelamiento de salarios con el sindicato de la armadora, y un conjunto limitado de estímulos a sus trabajadores. Este aguerrido sindicato ha aceptado en ocasiones anteriores ese compromiso: en las crisis de 1998 y de 2009 , lo cual concuerda con la gravedad imperante que representa la pandemia (Yonhap 2020g).

El problema también se manifiesta en términos demográficos, ya que la creciente población que concluye su vida laboral y la reducción de jóvenes que la sostengan con sus impuestos impondrá un gran reto en las finanzas públicas que ahora están volcadas a rescatar y conservar lo logrado. Se debe entonces aumentar de manera considerable la productividad laboral. Dado que Corea del Sur es una economía crecientemente dedicada a los servicios y cada vez menos a la manufactura, la pandemia tal vez pueda ser vista como una oportunidad de reconversión para utilizar tecnología digital como factor clave en la productividad y también como motor de crecimiento.

La pandemia ha propinado golpes también a las cadenas productivas globales. Aunque el sistema de organización corporativa característico de Corea le permita sortear los ciclos económicos distribuyendo la carga entre las filiales y proveedores de los grupos industriales, prolongar la irrupción de insumos extranjeros también es un problema serio. Si 
bien la crisis ha golpeado al sector productivo en general, ciertamente las principales perdedoras son las pequeñas y medianas empresas que están involucradas en dichos encadenamientos y dependen de la reactivación de la economía mundial para sobrevivir. Se calcula que alrededor de un quinto del valor de las exportaciones coreanas proviene de manera indirecta de la comercialización y proveeduría de pequeñas y medianas empresas (Mah 2018; Ministry of SMEs and Startups). Sin embargo, difícilmente lograrían subsistir sin ayuda externa o sin que se les incluya en algún paquete de financiamiento especial para la contingencia.

Pero aun cuando las medidas de contención de contagios han logrado mantener relativamente bajo control la segunda ola, con su conocida capacidad de reacción rápida para monitorear la movilidad y restringir la apertura de puntos críticos, los negocios locales ejercen una presión importante al gobierno de Moon Jae-in para aliviar algunas medidas de distanciamiento social. Por otro lado, siempre hay quienes argumentan que su forma y tino para bajar o elevar los niveles de alerta han sido inadecuadas para tener las infecciones diarias bajo control. Ante ello, Moon reconoció que el país "debe caminar sobre una cuerda floja entre el control del virus y la economía”, esto es, proteger la vida, y al mismo tiempo tratar de mantener a flote el mercado local mientras la economía mundial se recupera para revitalizar las exportaciones. Parece imposible atrapar los tres conejos y conservarlos, especialmente porque todo indica que el mundo está obligado a vivir con el virus por mucho tiempo. Sin embargo, si bien ha logrado paliar la crisis con subsidios al consumo y llevar a cabo medidas de distanciamiento más o menos estrictas, dependiendo de su rápida identificación y contención de los brotes de infección, esas medidas difícilmente pueden permanecer de manera indefinida.

El hecho de que el partido de Moon Jae-in haya ganado la mayoría de los asientos de la Asamblea Nacional en las elecciones de abril ciertamente le permite mayor margen de maniobra para la aprobación del presupuesto y de cuatro paquetes de apoyo financiero y fiscal para estimular el consumo y reactivar la economía. A pesar de la contracción del consumo doméstico en la primera mitad del año, la demanda ha logrado repuntar con respecto al registro del año anterior y se ha conservado el valor del dinero más que en otros lugares, muy probablemente gracias a las medidas fiscales y monetarias instrumentadas. Con la 
repartición de bonos o vouchers que sólo pueden usarse para el consumo, el dinero puede reciclarse en la economía local y más pequeños negocios pudieron reabrirse.

La inflación tampoco ha sido un problema tan grave, aunque los registros negativos también indican la falta de consumo y, por tanto, de crecimiento. Como en otros indicadores, marzo, abril y mayo han sido los meses más difíciles, pero puede verse una tendencia a la recuperación.

Precios al consumidor

\begin{tabular}{lccccccccccccc}
\hline \multicolumn{1}{c}{2019} & \multicolumn{1}{c}{2020} \\
\hline & Sep. & Oct. & Nov. & Dic. & Ene. & Feb. & Mar. & Abr. & May. & Jun. & Jul. & Ago. \\
\hline $\begin{array}{l}\text { Precios al consumidor } \\
\text { (m-m) }\end{array}$ & 0.4 & 0.2 & -0.6 & 0.2 & 0.6 & 0.0 & -0.2 & -0.6 & -0.2 & 0.2 & 0.0 & 0.6 \\
\hline \begin{tabular}{l} 
(a-a) \\
\hline
\end{tabular} & -0.4 & 0.0 & 0.2 & 0.7 & 1.5 & 1.1 & 1.0 & 0.1 & -0.3 & 0.0 & 0.3 & 0.7 \\
\hline
\end{tabular}

FUENTE: Ministry of Economy and Finance 2020c, 30.

Mientras tanto, el gobierno busca aprovechar la crisis para llevar a cabo un ajuste importante en la estructura económica y acelerar la salida de industria manufacturera para centrarse en las de servicios y de alta tecnología. Esto es, además de la ayuda directa a las familias, con dinero para el consumo en establecimientos locales y de los paquetes de estímulos crediticios y fiscales, en agosto se puso en marcha un ambicioso plan para estimular la economía con miras a crear un impulso duradero que dé paso a un ajuste de la estructura económica: a este plan se le llamó Nuevo Plan Coreano (NPC) (Korean New Deal). ${ }^{10}$ El NPC es una versión actualizada de política industrial basada en dos ejes: "Economía digital” y "Economía verde". Los estímulos consisten en apoyos financieros, ${ }^{11}$ fiscales y monetarios para la formación de recursos humanos y fortalecimiento de empresas en esas áreas para convertirlas en los "futuros motores de crecimiento". Se invertirán miles de millones de

\footnotetext{
${ }^{10}$ El NPC fue anunciado oficialmente el 14 de julio de 2020. La versión en inglés del Korea New Deal puede encontrarse en Ministry of Economy and Finance (2020b).

${ }^{11}$ El gobierno anunció el 3 de septiembre su plan de crear un Fondo para el Nuevo Plan Coreano de 20 billones de won, del que el sector privado puede disponer durante los siguientes cinco años. El fondo se compone 35\% de fondos públicos y $65 \%$ de fondos privados (Ministry of Economy and Finance 2020c, 52).
} 
dólares para acelerar la creación de empleos y promover la innovación industrial, formar 100000 especialistas en inteligencia artificial, programación, blockchain, biosalud, transporte inteligente y telecomunicaciones, y así contar con el capital humano para establecer y operar el sistema de big data, IA y redes 5G, que contribuyan a la mejora de infraestructuras para negocios a distancia, la procuración servicios sociales, y el fomento de startups enfocados en desarrollo digital y tecnologías verdes efícientes en uso de energía.

Como era de esperarse, el gobierno surcoreano ha sido (muy) proactivo en la estabilización de empleos y la recuperación económica mediante el NPC. Asimismo, sigue en pie la meta de reducir la inequidad con su política de expansión de seguridad social. El financiamiento de los paquetes de emergencia y de la política social proviene de la emisión de bonos estatales, reajustes de los gastos gubernamentales, la recaudación de impuestos a las grandes empresas y los ingresos por contribuciones a la seguridad social. Eso sí, se espera un déficit fiscal de $3.5 \%$ en 2020 y 4.5 para 2021 , y que la deuda de gobierno crezca de $39.8 \%$ a 56.7\% (Ministry of Economy and Finance 2020c, 40-41).

Aunado a los graves problemas económicos que la pandemia ocasionó y que permanecerán por varios años está el ya viejo problema del alza en el precio de la vivienda. A pesar de que en 2018 el gobierno surcoreano elaboró fuertes medidas fiscales sobre bienes inmuebles para los propietarios de múltiples viviendas y estrictas regulaciones de préstamos hipotecarios para frenar la subida de los precios de la vivienda en Seúl y en otras áreas, el problema persiste y la pandemia lo ha agravado. Según algunos especialistas, la burbuja inmobiliaria tarde o temprano explotará y causará graves daños a la economía familiar. En ese sentido, lo que más preocupa son los préstamos hipotecarios. La deuda familiar excesiva "tiene un efecto negativo en el crecimiento económico pues eventualmente inhibe el consumo: la profundización de las dificultades financieras para las familias, incrementan la posibilidad desarrollar ansiedad. [Así que] un evento inesperado tanto dentro como fuera de Corea puede detonar una crisis mayor [...]" Un especialista observa que "gran parte de las crisis financieras han sido ocasionadas por una creciente burbuja en el mercado inmobiliario por el incremento en los préstamos hipotecarios, y la creciente insolvencia provoca (eventualmente) que la burbuja se reviente" (Park 2020). En ese contexto, lo más probable 
es que el shock al que se refiere sea la crisis sanitaria que azota al mundo durante todo el 2020 y más allá.

Los problemas de la deuda doméstica y la creciente burbuja inmobiliaria se desarrollan en un mal momento, en especial cuando un gran número de negocios ha cerrado y la amenaza del desempleo masivo está permanentemente al acecho. Los principales establecimientos comerciales que cerrados al segundo trimestre (4.5\%) han sido restaurantes, tiendas de venta al menudeo y servicios de arreglo personal; en términos generales, los sectores más afectados han sido el turismo, el ocio y el entretenimiento. Dado que las empresas han permitido que muchos de sus empleados trabajen desde casa, el consumo en ese tipo de lugares se ha reducido y es prácticamente imposible pagar siquiera los gastos fijos, por lo cual resulta imposible continuar abierto (Choi, J-h 2020). La ayuda gubernamental ha logrado mantener a flote algunos establecimientos, pero el daño es demasiado grande como para poder salvar a todos. Precisamente esa situación es la que preocupa ante la crisis inmobiliaria que se avecina, ya que las familias que dependen de esos negocios podrían tener deudas hipotecarias sin capacidad de solventarlas.

A pesar del sombrío prospecto de recuperación económica en Corea del Sur y el resto del mundo, en la más reciente proyección económica publicada por la OCDE, Corea del Sur aparece como la economía que menos se contraerá durante este año con un crecimiento del PIB real de $-1.0 \%$ respecto al año anterior, sólo por detrás del 1.8\% de China (OECD 2020).

Y en medio de los grandes problemas nacionales y los intentos de mitigar la crisis, la saga del juicio en contra de Lee Jae-yong siguió su marcha. Él es el primogénito de Lee Keun-hee, chairman del grupo Samsung, quien murió el 25 de octubre de 2020, después de casi 6 años de permanecer en coma tras un accidente cardiovascular, por lo que el joven Lee se ha preparado como sucesor del liderazgo del conglomerado cuya riqueza equivale a un quinto del PIB de Corea del Sur. Como se recordará, en 2017 Lee Jae-yong fue arrestado por los supuestos vínculos de corrupción con Choi Soon-sil, la infame amiga de la depuesta presidenta Park Geun-hye, quien ahora se encuentra presa por abuso de poder, soborno, coacción y filtración de secretos del gobierno. Lee recobró temporalmente su libertad, pero fue sometido a otro proceso que lo acusa, junto con una decena de funcionarios de Samsung, de manipular información y registros contables que afectarían artificialmente el precio de 
acciones de ciertas empresas para llevar a cabo una fusión corporativa en 2015 en contra de los procedimientos legales y éticos. Dicha fusión daría a Lee Jae-yong mayor control sobre el grupo Samsung, consolidando así su posición como heredero definitivo y menoscabando los intereses y derechos de los accionistas minoritarios, especialmente por haber sido engañados.

El caso particular de este proceso de sucesión podría ser reflejo de un fenómeno que por años ha molestado a la sociedad coreana en general: la cercanía del poder económico, el político y hasta el judicial, y las implicaciones en la discrecionalidad en el cumplimiento de la ley en favor de esta red de influencias. Con gobiernos coreanos progresistas y liberales como el actual, supuestamente con menor apego a estas prácticas, es más común ver algún avance en materia de justicia económica; empero, en el pasado reciente Corea del Sur ha tenido gobiernos progresistas y liberales sin que se hayan podido erradicar. La historia de Lee Jae-yong no es entonces un caso extraordinario, pero por la obvia importancia de Samsung en la economía política surcoreana y la gran batería de recursos económicos y mediáticos que tiene a su disposición un grupo como ése, ha generado mucha atención y expectativa. El resultado del proceso judicial también podrá dar cuenta del punto de maduración de la democracia coreana.

\section{POLÍTICA}

Además de las implicaciones de la pandemia en la política surcoreana que, como mencionamos arriba, resultó favorable gracias al manejo adecuado de la crisis sanitaria y económica, el año todavía registró reverberaciones de escándalos del año anterior. El más notorio fue el caso del nombramiento de Cho Kuk como ministro de Justicia en septiembre de 2019, quien fue acusado por tráfico de influencias para ayudar a su hija a ingresar a la prestigiosa Universidad de Corea, lo cual empañó la imagen del actual gobierno. El ministro Cho renunció 35 días después de su nombramiento y fue reemplazado hasta el 5 de enero por la legisladora Choo Mi-ae, ex presidenta del Partido Democrático y ex jueza. Aún después de su renuncia, el caso continuó dividiendo la opinión pública y la fiscalía siguió investigando su presunta responsabilidad en casos de soborno con altos funcionarios de la alcaldía de Busan; Chung Kyung-sim, su esposa, también ha sido implicada en irregularidades 
financieras relacionadas con una inversión en un fondo de capital privado. Sabiendo cómo irrita a la gente este tipo de episodios, sean ciertos o no, la oposición también armó una acusación en contra de la ministra Choo, alegando que abusó de su poder al haber intervenido para que su hijo recibiera un trato preferencial durante su servicio militar en 2017; el 28 de septiembre de 2020 la acusación fue desechada por la fiscalía tras no encontrar evidencia suficiente que sustentara denuncia. Mientras las averiguaciones siguen su marcha, la credibilidad del gobierno va siendo golpeada y retrasa el avance en la agenda de reformas institucionales. Los casos anteriores se suman al del ex jefe del Tribunal Supremo, Yang Sung-tae, quien fuera imputado, detenido a inicios de 2019 y después liberado bajo fianza por cargos de abuso de poder y corrupción, al igual que otros diez ex jueces, varios de ellos conocidos por su fidelidad a grupos conservadores. La política surcoreana ha tenido entonces su dosis de entretenimiento político-judicial y deja ver el entramado de complicidades, divisiones políticas y prácticas aviesas que ni la sociedad más confuciana o el gobierno más progresista puede todavía erradicar.

A pesar del enrarecimiento del ambiente político, en diciembre se lograron aprobar reformas electorales que redujeron la edad para votar de 19 a 18 años e introdujo un sistema mixto de representación proporcional, cuyas reglas favorecen a partidos pequeños que no lograban traducir los numerosos votos que recibían en un número proporcional de escaños en la Asamblea Nacional (Yonhap 2019b). La intención de la nueva ley es resolver problemas antiguos de sobrerrepresentación y concentración de poder de los dos partidos más grandes y la carencia de diversidad entre los parlamentarios. Así, la reforma brinda oportunidades para que partidos jóvenes o minoritarios tengan participación en el Parlamento y fomenta mayor pluralidad, por ejemplo, la inclusión de candidatos con discapacidades o de desertores norcoreanos o activistas de otros temas comúnmente despreciados en la política parlamentaria surcoreana. Por supuesto, el nuevo sistema detonó la proliferación de partidos satélite a los partidos grandes (Partido Democrático y el Partido del Poder del Pueblo) ${ }^{12}$ para la asignación de asientos de acuerdo con el nuevo sistema (Kim 2020).

\footnotetext{
${ }^{12}$ El "Partido del Poder del Pueblo" es desde el 2 de septiembre de 2020 el nuevo nombre del principal partido opositor de identidad conservadora, conocido antes como Partido Futuro Unido (PFU). Según el comité directivo, se decidió cambiar el nombre con el fin de reforzar una imagen basada en la idea del "poder que viene del pueblo, que se ejerce para el pueblo y que une al pueblo en uno". El PFU era producto de la fusión del Partido de Libertad Surcoreana y partidos conservadores minoritarios ocurrida a mediados de febrero de 2020 (Yonhap 2020f).
} 
Con el contundente triunfo del Partido Democrático en las elecciones intermedias del 15 de abril de 2020 (Kim, H-s 2020), el gobierno de Moon Jae-in ha tenido bastante margen de maniobra para la aprobación de presupuestos con que responder a la crisis de la pandemia y el rescate económico, y supuestamente también para avanzar en las reformas de la físcalía, la policía y el Servicio de Inteligencia Nacional (SIN), pendientes desde el principio de su administración y que en parte fue entorpecida por el escándalo de Cho Kuk y su familia, entre otros. Una de las metas principales de las reformas es ajustar la actuación y la autoridad de la fiscalía y la policía, ya que el gobierno busca el establecimiento de una unidad independiente para investigar los delitos de corrupción por parte de funcionarios públicos de alto rango e introducir un sistema policial autónomo que opere de forma separada de la policía nacional, supervisada por el gobierno central, y otorgar a la policía más poder de investigación. Las reformas también buscan impedir que el SIN interfiera en la política nacional utilizando su capacidad e información en beneficio de algún político o entidad, algo muy común en la época autoritaria previa a los años noventa, pero que sigue siendo una posibilidad institucional de acuerdo con las reglas de operación del Servicio (Yonhap 2020i y 2020j). El apremio es grande, ya que cuenta con una oportunidad por la superioridad numérica en la Asamblea, pero también porque está a punto de entrar en la recta final de su mandato de cinco años y busca completar esas tareas interrumpidas también por las medidas de aislamiento y trabajo remoto ocasionado por la pandemia.

Las elecciones fueron precedidas por campañas poco convencionales, aunque no tanto por alguna innovación mercadológica o novedades en las plataformas electorales o el tipo de temas, sino por la postura al gigantesco reto que imponía la respuesta al coronavirus. Como era de esperar, el programa del Partido Democrático estaba focalizado en el eje económico del gobierno en torno al crecimiento propulsado por el ingreso de la mayoría de la población, resaltando las grandes desigualdades que caracterizan a la sociedad surcoreana, las cuales fueron expuestas internacionalmente gracias al éxito cinematográfico de Bong Joon-ho y su película Parásitos. En contraste, el principal partido de oposición centró su discurso en el supuesto fracaso de la política hacia Corea del Norte y las tensiones con Japón, entre otros asuntos internacionales que terminaron siendo de muy poca relevancia para el electorado. Quizá equivocadamente, el entonces llamado Partido Futuro Unido optó por dirigir la crítica al manejo gubernamental de la pandemia, señalando que se reaccionó con 
retraso y que debió bloquearse el acceso de viajeros del extranjero, especialmente de Wuhan, entre otras acciones consideradas erradas. Con la pandemia como el telón de fondo, las elecciones fueron más bien un fallo público al manejo de la crisis sanitaria. Como mencionamos arriba, el veredicto favoreció al gobierno de Moon Jae-in.

Sin embargo, aunque con el resultado de los comicios el partido en el gobierno contaba ya con la mayoría de los asientos en la Asamblea Nacional, no puede decirse que Moon Jae-in las tenía todas consigo. Si bien no hubo gran desgaste en la aprobación del presupuesto para enfrentar la pandemia, el descalabro económico inmediato y los planes de largo plazo para la reconversión industrial, otras reformas institucionales como las mencionadas arriba todavía no han logrado materializarse. Entre las frustraciones más recientes se encuentra el intento de reforma de la plantilla médica del país. El plan propone expandir en 4000 las cuotas de admisión en las escuelas de medicina a partir de 2022 y durante los próximos 10 años, y abrir una nueva escuela pública de medicina. El gremio médico y de estudiantes de medicina llevaron a cabo protestas en contra de la iniciativa que aumentará el número de médicos y reducirá sus privilegios, no obstante que pareciera haber una notoria necesidad de personal en el sistema de salud, especialmente en áreas rurales. Por su parte, los médicos argumentan que más bien debería mejorarse la infraestructura, el equipamiento y las condiciones laborales para que la práctica médica en áreas menospreciadas sea atractiva (Kang 2020; véanse también Cha 2020 y Kim, A. 2020). Y mientras los estudiantes se unieron al boicot de los médicos, varios de ellos dejaron pasar la fecha de registro al examen estatal para obtener licencia profesional y, por lo tanto, no pudieron realizarlo. El gobierno se ha negado a dar una segunda oportunidad para presentar el examen, a pesar de la solicitud de asociaciones que representan a los mayores hospitales generales del país, las cuales, irónicamente, argumentan que no contar con los 2700 nuevos doctores sería una situación seria. ${ }^{13}$ La opinión está dividida y queda pendiente el diálogo entre las partes. En lo que eso ocurre, el plan de reforma regresó al archivo de reformas pendientes del gobierno.

\footnotetext{
${ }^{13}$ La casa presidencial reportó haber recibido una petición firmada por más de 570000 personas para que el gobierno no permita a los estudiantes presentar el examen, mostrando al menos que una parte de la sociedad critica la intransigencia y aparente mezquindad de ciertas agrupaciones médicas (Yonhap 2020k).
} 
También quedará pendiente conocer la verdad sobre la acusación de acoso sexual a Park Won-soon, quien se quitó la vida después de que su ex secretaria presentara la denuncia. Antes de suicidarse, Park se desempeñaba como alcalde de Seúl y era un potencial candidato del Partido Democrático a las elecciones presidenciales de 2022. Aunque el Gobierno Metropolitano de Seúl anunció el plan para lanzar una investigación, la materia quedaría sin la parte acusada, por lo que de seguir tendría sólo un carácter simbólico, pero necesario para fortalecer el movimiento me too que tomó auge en Corea del Sur desde mediados de 2018.

\section{RELACIONES EXTERIORES}

La respuesta de Corea del Sur ante la crisis por la pandemia del covid-19 ha sido considerada ejemplar y las autoridades de salud han estado muy ocupadas proveyendo consejo y capacitación internacional a quien lo solicite. Por eso es frecuente encontrar en la prensa nacional reportes sobre llamadas de funcionarios surcoreanos de alto nivel acordando programas con gobiernos de todo el mundo para compartir su experiencia. Esta forma de cooperación internacional ha contribuido a elevar el prestigio del país, aunado al trabajo del Instituto Internacional de Vacunas establecido desde $1997^{14}$ y cuya sede está en Corea. Además, Corea del Sur participa activamente en las instalaciones de Covax liderada por la Organización Mundial de la Salud y la organización promotora de vacunas Gavi.

Destaca también en este año la tensión con Estados Unidos, especialmente por la insistencia de Donald Trump de obligar al gobierno surcoreano a quintuplicar el pago para mantener a las tropas estadunidenses estacionadas en su territorio. Esta demanda del presidente Trump unió a las fuerzas políticas coreanas, aun las de la oposición conservadora y simpatizante, con sus semejantes en Washington, en contra de aceptar tal aumento, lo que todavía en octubre tenía detenidas esas negociaciones. Según declaró Robert Abrams, comandante de las fuerzas combinadas Corea del Sur-Estados Unidos (USFK), al proceso de traspaso del mando militar en tiempos de guerra del ejército estadunidense a Corea del Sur aun le quedaba "un largo camino por recorrer" (KBS 2020). Cabe mencionar que la política

\footnotetext{
${ }^{14}$ El Instituto Internacional de Vacunas (IIV) es una organización internacional sin fines de lucro establecida en 1997 y dedicada al descubrimiento, desarrollo y suministro de vacunas seguras, efectivas y asequibles para la salud pública global, particularmente para países de bajos ingresos. Más sobre el IIV en: https://www.ivi.int/
} 
de acercamiento a Corea del Norte por parte de Corea del Sur fue puesta en aprietos por su principal aliado, tras su fracaso de forzar la desnuclearización de Corea del Norte.

Por otra parte, si bien las relaciones entre Corea del Sur y China han sufrido por la guerra comercial con Estados Unidos, en la que Corea queda en fuego cruzado sin mucho que pueda hacer, las relaciones con Japón llamaron particularmente la atención durante el año, en especial por la continuidad en las tensiones comerciales por un conflicto histórico no resuelto. La novedad presentada a finales de agosto y principios de septiembre es la renuncia de Shinzō Abe como primer ministro.

El 28 de agosto, Shinzō Abe anunció su renuncia al puesto que había ocupado ininterrumpidamente desde hacía más de siete años. Después de la competencia entre las facciones del Partido Liberal Democrático, Yoshihide Suga fue seleccionado como su sucesor y el 16 de septiembre se convirtió en el 99 primer ministro. Suga no sólo heredará un conjunto de políticas largamente establecidas, de las cuales él mismo fue corresponsable de idear y ejecutar, sino que los cargos clave del gobierno continuarán ocupados por los mismos funcionarios y el resto por personal que ya había sido parte del gabinete de Abe, por lo que muy probablemente daría continuidad a la tendencia conservadora de la política exterior japonesa, al menos durante el año de su interinato. Esto es, se espera un cambio de estilo más que de contenido, en el que Suga sería un factor de estabilidad y no tanto de innovación en la política interna y exterior. Además, debido a la crisis económica creada por la pandemia, muy probablemente la mayor parte de la atención del nuevo gobierno japonés se centrará en resolver los problemas económicos internos $\mathrm{y}$, por tanto, menos interés en emprendimientos de política exterior.

A pesar de algunas desavenencias muy arraigadas, como la disputa por las islas Dokdo y las mujeres de confort, Corea del Sur y Japón lograron mantener un diálogo relativamente fluido, un creciente intercambio cultural y una sólida relación económica, en particular desde las décadas de 1990 y 2000. Durante el gobierno de Shinzō Abe, sin embargo, especialmente en los últimos dos años, la relación se deterioró por interpretaciones opuestas de la historia entre ambos países. Después de que en octubre de 2018 la Corte Suprema de Corea del Sur emitiera su resolución acerca de la compensación económica a quienes trabajaron en condiciones de esclavitud en empresas japonesas durante el periodo de 
ocupación, ${ }^{15}$ las relaciones alcanzaron un punto fatal. La negativa de las empresas y el gobierno nipón argumentaba que las reclamaciones de la ocupación en la primera mitad del siglo XX ya se habían resuelto y compensado en el acuerdo de 1965 por el cual Corea del Sur y Japón restablecieron relaciones diplomáticas; además, la respuesta incluyó el endurecimiento de controles a la exportación de insumos clave para la producción de equipos electrónicos de empresas coreanas, argumentando razones de seguridad nacional que no fueron debidamente documentadas ni justificadas. Por otro lado, un mes después Tokio eliminó a Corea del Sur de su "lista blanca" de socios comerciales preferenciales. El gobierno surcoreano respondió quejándose contra Japón ante la OMC, removiéndolo de su propia lista de socios preferenciales y anunciando la cancelación del pacto de intercambio de inteligencia militar con Japón establecido en 2016, con lo cual Estados Unidos fue forzado a integrarse como mediador. Por lo tanto, de una demanda legítima para los coreanos, la cual fue obstruida durante años por motivos políticos de parte de gobiernos conservadores en Corea del Sur, se desató una guerra comercial que no tuvo solución durante el año que analizamos aquí. ${ }^{16}$ El conflicto incluso se deterioró aún más causando daños importantes a los encadenamientos productivos entre ambas economías, intensificado en 2020 por la pandemia de covid-19 y las tendencias proteccionistas que secundaban la propia del gobierno de Donald Trump. Y mientras la querella jurídica era discutida en el plano político, las empresas coreanas suplieron a las japonesas con proveedores locales e incluso con empresas japonesas que establecieron instalaciones cerca de Seúl.

Dada la conformación del "nuevo" gabinete no se espera una mejoría sustancial en las relaciones bilaterales con Corea. No obstante, una vez seleccionado como primer ministro, Yoshihide Suga manifestó su interés en mantener opciones de diálogo abiertas, y ese mismo día Moon Jae-in le envió una carta de felicitación en la que expresaba su deseo de desarrollar más la relación y su disposición de mantener el diálogo y la comunicación. La carta fue respondida cinco días después con otra misiva en la que Suga manifestaba su

\footnotetext{
${ }^{15}$ Muchos coreanos fueron obligados a trabajar en fábricas y minas japonesas durante la Segunda Guerra Mundial, cuando Corea era gobernada por el gobierno de ocupación japonés. El 30 de octubre de 2018, la Corte Suprema de Corea emitió una resolución histórica al ordenar a Nippon Steel \& Sumitomo Metal (renombrado Nippon Steel en 2019) pagar el equivalente a 82000 dólares a cada una de las víctimas de trabajos forzados durante ese periodo. El 29 de noviembre del mismo año emitió una resolución similar contra Mitsubishi Heavy Industries, bajo el argumento de que los derechos individuales para recibir compensación no habían expirado.

${ }^{16}$ A pesar del diálogo de alto nivel que alivió un poco la tensión y de la reunión informal entre Moon Jae-in y Shinzō Abe que ocurrió al margen de una cumbre regional en Bangkok a finales de 2019.
} 
esperanza de desarrollar relaciones "orientadas al futuro", con un "vecino importante" como Corea del Sur (Yonhap 2020h). Moon y Suga conversaron telefónicamente el 24 de septiembre, pero a la luz de lo reportado, las consabidas posiciones no parecen haber cambiado, a pesar de la disposición al diálogo y a no dejar las cosas en su estado actual. ${ }^{17}$

A juzgar por el posicionamiento del gobierno japonés, no parece que habrá solución significativa en lo que resta de 2020, aunque habrá que ver si Suga puede distanciarse del revisionismo histórico de Abe y encontrar una salida diplomática. Suga podría presentar un nacionalismo un poco más moderado y actuar de manera pragmática de tal forma que le permita vincularse de manera constructiva con Corea, especialmente en el restablecimiento de la relación comercial y presentar una posición más firme hacia China. Si Joe Biden gana la presidencia estadunidense, eso podría ser un factor de cambio en las relaciones entre Corea del Sur y Japón, si es que Biden tiene voluntad de interferir para posibilitar la cooperación en la región (para contrarrestar el poder de China y coordinar mejor las acciones hacia Corea del Norte). Podría establecerse cierto ímpetu para mejorar la relación.

\section{RELACIONES INTERCOREANAS}

Las relaciones intercoreanas parecían mantenerse medianamente estáticas y con un diálogo limitado durante la segunda mitad de 2019, sobre todo afectado tras el fracaso del gobierno estadunidense por cambiar las motivaciones de Pyongyang para mantener el programa nuclear. La situación empeoró cuando organizaciones civiles surcoreanas que abogan por los derechos humanos en Corea del Norte lanzaron globos con propaganda antirrégimen. El gobierno en Seúl se enfrentó con el dilema de escudarse con el argumento del derecho a la libre expresión de sus ciudadanos o reprocharles la transgresión y suspender las licencias de dichas organizaciones por perjudicar la política de acercamiento (la cual obviamente desaprueban). Lo cierto es que, mientras se tomaron acciones más claras, Kim Yo-jong, hermana del actual líder Kim Jong-un, supuestamente ordenó destruir la oficina de enlace surcoreana en el complejo industrial de Kaesong. Las tensiones aumentaron, junto con recriminaciones mutuas, y se interrumpieron las líneas de comunicación con Seúl por

\footnotetext{
${ }^{17}$ En la conversación con Moon, Yoshihide Suga dijo que Seúl debe "tomar responsabilidad y ofrecer una solución”. Véase Yonhap 20201.
} 
iniciativa de Pyongyang. Las relaciones intercoreanas eventualmente se calmaron, pero el incidente ocasionó que el ministro de Unificación renunciara, lo cual condujo a varios cambios en el gabinete de seguridad.

Moon Jae-in percibió una oportunidad para dar un nuevo impulso a las relaciones con Corea del Norte en su discurso en la 75 a reunión (virtual) anual de la Asamblea General de Naciones Unidas el 23 de septiembre de 2020. El discurso de Moon (2020) será recordado por su tono humanista y el llamado a priorizar la cooperación mediante mecanismos multilaterales para responder a amenazas no tradicionales a la seguridad humana como desastres naturales, terrorismo o crímenes cibernéticos, pero también en la lucha contra el calentamiento global, la inclusión económica y, claro, frenar el avance del coronavirus. Moon dijo que la crisis de la covid-19 "presenta una amenaza más grande que una guerra, por lo que se nos ha recordado con severidad que la seguridad de los países vecinos está directamente ligada a la nuestra”. Después de eso propuso la creación de una organización regional para enfermedades infecciosas y salud pública con una visión inclusiva desde la cual se puedan coordinar esfuerzos colectivos para proteger la vida y la seguridad de los países más vulnerables, como Corea del Norte, y con ello defender la de los propios países que la integren. Ya se verá si esa iniciativa prospera y cómo pueda insertarse en la arquitectura multilateral regional existente.

Pero por lo que Moon Jae-in será más recordado es la petición del apoyo de la comunidad internacional para que se firme la paz, para luego entonces proceder a la desnuclearización. "La declaración del fin de la guerra abrirá, efectivamente, la puerta para la desnuclearización completa [y el establecimiento] de un régimen de paz en la península de Corea", dijo Moon. La posición del gobierno surcoreano expresada así es, sin embargo, opuesta a la doctrina estadunidense que dicta la desnuclearización como condición para proceder a la discusión sobre el régimen de paz; posiblemente por esa razón no tuvo mucho eco entre los aliados. En Estados Unidos incluso se le calificó como un discurso "fuera de sincronía" con respecto a la posición estadunidense y la práctica habitual de presentar una respuesta uniforme (Choi, S-j 2020a; Ser 2020). Moon presentó una apuesta audaz y arriesgada que refleja su compromiso para remplazar el armisticio que define el régimen de seguridad actual, pero también una lectura no convencional sobre las motivaciones de 
Pyongyang para desarrollar su programa nuclear, y posiblemente también intentar marcar su distancia respecto a la postura tradicional que evidentemente no ha dado resultado en más de 25 años. Remató confirmando su disposición incansable al diálogo y la cooperación para resolver las tensiones intercoreanas, lo cual también implica una separación de la condicionalidad del diálogo a la desnuclearización completa, irreversible y verificable.

A pesar de una respuesta poco alentadora de los aliados al llamado de Moon Jae-in, el presidente conversó telefónicamente con Vladimir Putin y, según se informó desde la casa presidencial, el mandatario ruso declaró estar dispuesto a cooperar para mejorar las condiciones de paz de la península, pero no se reportó si estaba de acuerdo con la propuesta concreta de Moon acerca de la secuencia para avanzar en el proceso. A finales de septiembre el gobierno envió a Washington al más alto funcionario para asuntos nucleares, Lee Do-hoon, con objeto de plantear varias propuestas hacia la reanudación del diálogo con Corea del Norte. No se dieron detalles de la reunión, pero seguramente se presentó la iniciativa surcoreana de declarar el fin de la guerra entre otros posibles caminos de acercamiento. La reunión se calificó como "constructiva" y su interlocutor, el subsecretario de Estado estadunidense, Stephen Biegun, expresó diplomáticamente que se expusieron "ideas creativas", mas requerían de la voluntad de Corea del Norte para realizarse. Queda entonces claro que Estados Unidos continuará con su posición habitual.

Empero, mientras el presidente Moon Jae-in pronunciaba el discurso que buscaba abonar al mejoramiento de las relaciones intercoreanas, un funcionario surcoreano del Ministerio de Asuntos Marítimos y Pesca que se encontraba supuestamente a la deriva flotando sobre un objeto no identificado en las cercanías de la controvertida línea Limítrofe del Norte murió por disparos de soldados norcoreanos. Según reportes de Seúl, el funcionario estaba previamente a bordo de un buque de inspección en las aguas frente a la isla de Yeonpyeong, pero había sido reportado como desaparecido antes del mediodía del lunes 21 de septiembre.

Al día siguiente de darse a conocer el incidente que causó conmoción y furia, el gobierno surcoreano calificó el asesinato como un "incidente impactante que no se puede tolerar por ningún motivo" y acusó al ejército norcoreano de violar el "espíritu" del pacto militar intercoreano, condenando la sinrazón de asesinar a un surcoreano "desarmado y sin 
intenciones de resistirse". ${ }^{18}$ Naturalmente, también causó una avalancha de críticas a la política de acercamiento de Moon Jae-in, especialmente del Partido del Poder del Pueblo, que buscó capitalizar la muerte del funcionario para su provecho político.

Como un acto inusual que podría mitigar el deterioro de las relaciones intercoreanas desde el lanzamiento de globos con propaganda antirrégimen por grupos surcoreanos, Kim Jong-un envió una carta dirigida al presidente y al pueblo vecino en la que dijo lamentar el "desafortunado" incidente, empleando dos veces la expresión "lo siento". (Cabe mencionar que ante el alto riesgo de la covid-19, Corea del Norte optó por cerrar sus fronteras, por lo que hay instrucciones de eliminar la amenaza.) En la carta explicó su versión de los hechos, según la cual un hombre "no identificado" cruzó sin autorización la frontera marítima y no dio respuesta satisfactoria al control verbal de seguridad, por lo que la guardia fronteriza detonó salvas y, ante lo que parecía un intento de escape, le dispararon directamente con balas. Como recurso para disminuir la tensión, la carta indica que dará instrucciones para que ese tipo de acciones queden registradas apropiadamente y así evitar errores y malentendidos. Esto último se dijo seguramente por el hecho de que el gobierno surcoreano señaló que tanto el cuerpo como el material con el que flotaba el funcionario habían sido recuperados e incinerados por los soldados, lo cual no coincide con el reporte norcoreano de que sólo se incineró dicho material como parte del protocolo de protección contra la covid-19, mas no encontraron el cuerpo del funcionario, sólo sangre.

Una vez más, el incidente no pudo llegar en peor momento, pues fortalece a la oposición, que critica al gobierno de Pyongyang y deja mal parado a Moon Jae-in, quien apenas había solicitado a la sociedad internacional su apoyo al proceso de paz y prosperidad duradera en la península. La respuesta de Kim Jong-un, sin embargo, puede ayudar un poco a salvar la cara de Moon y, posiblemente, dejar alguna puerta entreabierta para continuar el compromiso de diálogo del gobierno surcoreano. El tema tomará algún tiempo para esclarecerse y Corea del Sur demandó que se lleve a cabo una investigación conjunta, pues evidentemente hay desconfianza mutua de ambos informes. ${ }^{19} \mathrm{El}$ asunto se complicó porque

\footnotetext{
18 Técnicamente, el caso no parece constituir una violación al acuerdo de reducción de la tensión militar intercoreana firmado el 19 de septiembre de 2018, que pide detener todos los actos hostiles entre sí, por lo que juzgar que se violó el "espíritu" significa que "derriba todo lo que el pacto representa" y eso es más grave que incumplir alguna cláusula del mismo, según dijo el vicepresidente del Instituto Asan para Estudios Políticos, Choi Kang. Véase Choi, S-j $2020 \mathrm{~b}$.

${ }^{19}$ Hasta la entrega de este escrito la solicitud de Seúl no había sido respondida.
} 
no se encontró el cuerpo (aun cuando supuestamente tenía puesto un chaleco salvavidas), y hay muchas inconsistencias sobre las posibles razones por las que se encontraba flotando en aguas de territorio norcoreano, sin identificación, después de haber estado los días previos en un buque, sobre si quería desertar al Norte, o si en realidad fue encontrado por un buque norcoreano y sometido a algún interrogatorio para posteriormente dejarlo en el agua y dispararle; mientras tanto, habrá que seguir observando el desarrollo de la investigación y sus consecuencias para las relaciones intercoreanas y las perspectivas de consolidación de la paz, uno de los principales objetivos del gobierno surcoreano. Aunque Pyongyang haya admitido su responsabilidad en el asesinato, difícilmente se podrá tener una respuesta satisfactoria para todas las partes, lo cual complica la política de acercamiento benigno del gobierno de Moon.

Juan Felipe López Aymes es investigador titular en el Centro Regional de Investigaciones Multidisciplinarias de la UNAM, donde participa en el programa Cambio Mundial, Globalización y Desarrollo. Doctor en Relaciones Internacionales (Universidad de Sussex, Reino Unido), maestro en Estudios Internacionales (Universidad Yonsei, Corea) y licenciado en Relaciones Internacionales (Facultad de Ciencias Políticas y Sociales, UNAM). Es miembro del Sistema Nacional de Investigadores, nivel 2. Sus temas de investigación son la economía política de la cooperación internacional para el desarrollo y la relación de Asia Pacífico y América Latina; economía política comparada en el noreste de Asia; economía política del desarrollo en el caso de Corea del Sur y las corporaciones transnacionales en Asia Pacífico. Es autor del libro Corea del Sur: economía política del cambio institucional y de diversos artículos y capítulos de libros sobre institucionalismo, economía política coreana, así como temas relacionados con los mecanismos de cooperación económica en Asia Pacífico.

jflopezaymes@crim.unam.mx 


\section{REFERENCIAS}

Babones, Salvatore. 2020. “Countries Rolling Out Coronavirus Tracking Apps Show Why They Can't Work.” Foreign Policy, mayo 12, 2020. https://foreignpolicy.com/2020/ 05/12/coronavirus-tracking-tracing-apps-cant-work-south-korea-singaporeaustralia/

Cha, Sangmi. 2020. "South Korean doctors strike over plan to boost medical student numbers." Reuters, agosto 6, 2020. https:/www.reuters.com/article/us-health coronavirus-southkorea-doctors-idUSKCN2530HK

Choi, Jong-hoon. 2020. "Seoul lost around 20,000 businesses between first and second quarters of 2020." Hankyoreh, septiembre 8, 2020. http://english.hani.co.kr/ arti/english edition/e business/961298.html

Choi, Si-young. 2020a. "Moon's call for end-of-war declaration 'out of sync' with US: experts." The Korea Herald, septiembre 24, 2020. http://www.koreaherald.com/ view.php?ud=20200924000831

Choi, Si-young. 2020b. "N. Korea breached inter-Korean military pact: experts." The Korea Herald, septiembre 25, 2020. http://www.koreaherald.com/view.php?ud=20200925 $\underline{000730}$

Kang, Tae-jun. 2020. "As Covid-19 Surges in South Korea, Doctors Are Furious Over Government Training Plan.” The Diplomat, septiembre 3, 2020. https://thediplomat. com/2020/09/as-covid-19-surges-in-south-korea-doctors-are-furiousovergovernment-training-plan/

Kim, Arin. 2020. "Why are Korean doctors striking?" The Korea Herald, agosto 12, 2020. http://www.koreaherald.com/view.php?ud=20200811000941

Kim, Hyo-sun. 2020. “S. Korea's ruling Democratic bloc head for landslide victory in general election held amid Covid-19 outbreak." Arirang News, abril 16, 2020. https://www. arirang.com/News/News_View.asp?nseq $=256459$

Kim, Youngmi. 2020. "South Korea: Elections Amid a Pandemic.” The Diplomat, abril 1, 2020. https://thediplomat.com/2020/03/south-korea-elections-amid-a-pandemic 
Kong, Kanga y Lee, Heesu. 2020. "Korea Crushed a Huge Virus Outbreak. Can It Beat a Second Wave?” Bloomberg, junio 12, 2020. https://www.bloomberg.com/news/ articles/2020-06-12/korea-crushed-a-huge-virus-outbreak-can-it-beat-a-secondwave

Korea Automobile Manufacturers Association (KAMA). 2020. "Automobile Statistics (August 2020).” Korea Automobile Manufacturers Association. http://www.kama. or.kr/BoardController?cmd=V\&boardmaster_id=months_e\&gubun=eng\&board_id= $\underline{451 \& \text { menunum }=0081 \#}$

KBS. 2020. "Comandante de USFK: 'mucho por recorrer en traspaso de mando militar'." Korea Broadcasting System World Radio, septiembre 14, 2020. http://world.kbs. co.kr/service/news_view.htm?lang $=$ s\&Seq_Code $=72700$

KDCPA. 2020. "Press Release 269: Updates on Covid-19 in Republic of Korea." Korea Disease Control and Prevention Agency, octubre 4, 2020. http://ncov.mohw. go.kr/en/tcmBoardView.do?brdId=12\&brdGubun=125\&dataGubun=\&ncvContSeq $=3791 \&$ contSeq=3791\&board_id=\&gubun=

Mah, Jai S. 2018. "Korean Policies for SMEs Development and Internationalization.” En Innovation and SME internationalization in Korea and Latin America and the Caribbean: Policy experiences and areas for cooperation, coordinado por Sebastián Herreros, Keiji Inoue y Nanno Mulder, 97-120. Santiago: Comisión Económica para América Latina y el Caribe.

Ministry of SMEs and Startups. https://www.mss.go.kr/site/eng/main.do

Ministry of Economy and Finance. 2020a. Republic of Korea Economic Bulletin 42 (5). https://english.moef.go.kr/pu/selectTbPublicDtl.do?boardCd=P0002\&seq=

Ministry of Economy and Finance. 2020b. "Government Releases an English Booklet on the Korean New Deal” Development Finance Bureau - Green Climate Policy Division, julio 28, 2020. https://english.moef.go.kr/pc/selectTbPressCenterDtl.do?boardCd= $\underline{\mathrm{N} 0001 \& \text { seq }=4948}$

Ministry of Economy and Finance. 2020c. Republic of Korea Economic Bulletin 42 (9): 51. https://english.moef.go.kr/pu/selectTbPublicDtl.do?boardCd=P0002\&seq= 
Ministry of Economy and Finance. 2020d. Republic of Korea Economic Bulletin 42 (10). https://english.moef.go.kr/pu/selectTbPublicDtl.do?boardCd=P0002\&seq=

Moon, Jae-in. 2020. “Address by President Moon Jae-in at 75th Session of United Nations General Assembly.” Cheong Wa Dae Official Residence, septiembre 23, 2020. http://english1.president.go.kr/BriefingSpeeches/Speeches/881

Park, Hyun. 2020. "What's behind S. Korea's explosive increase in household debt?" Hankyoreh, septiembre 14, 2020. http://english.hani.co.kr/arti/english_edition/e business/962114.html

OECD. 2020. “OECD Economic Outlook, Interim Report. Coronavirus (Covid-19): Living with uncertainty" (septiembre). https://read.oecd-ilibrary.org/economics/oecd-economic outlook/volume-2020/issue-1_34ffc900-en\#page1

Pastreich, Emanuel. 2020. "The Impact of Covid-19 in South Korea." Korea Economic Institute, abril 10, 2020. http://keia.org/the-peninsula/the-impact-of-covid-19insouth-korea

Ser, Myo-ja. 2020. “Moon's UN speech falls flat.” JoongAng Daily, septiembre 23, 2020. https://koreajoongangdaily.joins.com/2020/09/23/national/politics/Moon-JaeinUNKorean-War/20200923181400387.html

Song, Jung-a, Kang, Buseong y White, Edward. 2020. "A warning from South Korea: the 'fantasy' of returning to normal life." Financial Times, junio 15, 2020. https://www.ft.com/content/d68d6292-0486-4bfc-bf5c-54ce850a3f7a

World Bank. 2020. "Country Analysis." World Integrated Trade Solution. http://wits. worldbank.org/visualization/Country-Analysis-Visualization.html

Yonhap. 2019a. "Las diez noticias nacionales más importantes de 2019 seleccionadas por la Agencia de Noticias Yonhap." Agencia de Noticias Yonhap, diciembre 18, 2019. https://sp.yna.co.kr/view/ASP20191218001800883?section=search

Yonhap. 2019b. "La Asamblea Nacional aprueba el proyecto de ley de reforma electoral." Agencia de Noticias Yonhap, diciembre 27, 2019. https://sp.yna.co.kr/view/ $\underline{\text { ASP20191227002700883? section }=\text { search }}$ 
Yonhap. 2020c. "Corea del Sur considera pulseras para prevenir que las personas en autocuarentena salgan afuera." Agencia de Noticias Yonhap, abril 7, 2020. https://msp.yna.co.kr/view/MYH20200407012100883?section=search

Yonhap. 2020d. "S. Korea exports wristband trackers for quarantine violators." Yonhap News Agency, mayo 20, 2020. https://en.yna.co.kr/view/AEN20200520005000320? $\underline{\text { section }=\text { search }}$

Yonhap. 2020e. "Hyundai suspende sus líneas de producción del Palisade y GV80 por problemas en la cadena de suministro de componentes." Agencia de Noticias Yonhap, junio 15, 2020. https://m-sp.yna.co.kr/view/ASP20200615003500883?section= economy/index

Yonhap. 2020f. "El principal partido opositor cambia de nombre a Partido del Poder del Pueblo." Agencia de Noticias Yonhap, septiembre 2, 2020. https://sp.yna.co.kr/view/ $\underline{\text { ASP20200902003500883? section=search }}$

Yonhap. 2020g. "Hyundai Motor y su sindicato acuerdan congelar los salarios en medio de la pandemia." Agencia de Noticias Yonhap, septiembre 21, 2020. https://msp.yna.co.kr/view/ASP20200921004200883?section=economy/index

Yonhap. 2020h. "Suga espera tener lazos 'orientados al futuro' con Corea del Sur en una carta dirigida al presidente Moon.” Agencia de Noticias Yonhap, septiembre 21, 2020. https://m-sp.yna.co.kr/view/ASP20200921003900883?section=national/index

Yonhap. 2020i. "Moon urge a seguir impulsando la reforma de la fiscalía, la policía y la agencia de inteligencia." Agencia de Noticias Yonhap, septiembre 21, 2020. https://sp.yna.co.kr/view/ASP20200921003800883?section=search

Yonhap. 2020j. "El jefe del NIS dice que la agencia nunca se involucrará en la política nacional." Agencia de Noticias Yonhap, septiembre 21, 2020. https://sp.yna.co. $\underline{\mathrm{kr} / \mathrm{view} / \mathrm{ASP} 20200921003500883 ? \mathrm{section}=\mathrm{search}}$

Yonhap. 2020k. "Govt, medical sector still haggling over state licensing exam." Yonhap News Agency, septiembre 25, 2020. https://en.yna.co.kr/view/AEN20200925007300 320? section $=$ search 
Yonhap. 20201. “Moon expresa su esperanza de alcanzar una solución ‘óptima' para el asunto del trabajo forzado en tiempos de guerra durante la conversación con Suga." Agencia de Noticias Yonhap, septiembre 24, 2020. https://sp.yna.co.kr/view/ASP202009240 03500883? section=national/index 